\title{
Inaugural editorial: Military Medical Research
}

\author{
Guo-Quan Ren
}

\begin{abstract}
Military medicine is one of the most innovative part of human civilization. Along with the rapid development of medicine and advances in military techniques, military medicine has become the focus and intersection of new knowledge and new technologies. Innovation and development within military medicine are always ongoing, with a long and challenging path ahead. The establishment of "Military Medical Research" is expected to be a bounden responsibility in the frontline of Chinese military medicine.
\end{abstract}

Keywords: Military medicine, Open access, Peer review

Military medicine is one of the most innovative part of human civilization. Along with the rapid development of medicine and advances in military techniques, military medicine has become the focus and intersection of new knowledge and new technologies. Innovation and development within military medicine are always ongoing, with a long and challenging path ahead. The establishment of Military Medical Research is expected to be a bounden responsibility in the frontline of Chinese military medicine.

Practicing international humanitarianism will be the keynote of the Journal. Since ancient times, regardless of the changes in the social forms, science and technology, and the type of weaponry and war, battle launched by human beings against the pain and death from war, natural disasters, and disease has never stopped. Military medicine has always shouldered the sacred mission of disease prevention, life-saving emergency rescue, and innovation of medical technology. Currently, with the wide spread of globalization, the spectrum of human diseases has been undergoing profound changes. Chronic diseases, such as new infectious diseases and cancer, have become the greatest threats to human health. SARS, H7N9, and other novel viruses have served as a warning to human beings over and over again. Earthquakes, tsunamis, floods, and other natural disasters have also raised new challenges to military medical rescue. Although patients vary in nationality, medicine has no national borders in dealing with

Correspondence: renguoquan@plamj.org

Health Department, General Logistics Department, Chinese People's Liberation Army (PLA), Beijing, China these new health threats. A tight and in-depth global cooperation among military medical professions becomes an urgent need. Therefore military medical communities in different countries can take the advantage of our journal to share and communicate, which, we believe, is the effective way to promote the innovation and development of military medicine as well as an important manifestation of the practice of international humanitarianism.

Innovation to military medicine will be the everlasting theme of the Journal. Our journal will be dedicated to promoting the global development and progress of military medicine, with a focus on reporting cutting-edge and practical innovative achievements in domestic and international military medicine, and with the goal of building up a worldclass journal to integrate technicality, advancement and practicability. We will adhere to highlighting the characteristics of military medicine and focusing on the development of advanced technology in both military and civil medicine, with consideration of the leading achievements and the latest developments in both clinical and fundamental field. Within the columns including Editorials, Research highlights, Perspectives, Special issues, Original articles, Reviews, and Letters to the editor, we will dedicatedly provide the latest academic achievements in the field of military preventive medicine; internal medicine, field surgery; nuclear, biological, and chemical (NBC) medicine; military medicine for special circumstances; military mental health; aerospace and maritime medicine; basic military medicine as well as in advanced technology; medical rescue in disasters; 
military training medicine; and health services, etc., to domestic and international senior practitioners of clinical practice, research, education, and management of military medicine and related fields. We will contribute to the establishment of a new communication platform for military medicine in the world, thereafter developing new approaches to international cooperation and promoting continued global innovation.

Promote international communication and cooperation will be our guiding principle. The establishment of Military Medical Research is also an attempt to create a new channel for international communication and cooperation with Chinese military medicine. Regarding the academic resources of the journal, adhering to the concept of "running the journal for scientists and by scientists", we will include the best military medical experts in China and extensively invite international academic authorities in military medicine as our editorial board members to strengthen the academic support for the journal. Regarding the operation and management, we will cooperate with renowned publishing groups of the world to innovate and improve the management mode with an international perspective, to optimize and integrate the operating mechanism beneficial for open communication, and to be rapidly integrated into the international publishing system, combined with our efforts to enhance the visibility and influence of our own brand. Regarding quality standards, we will actively and extensively cooperate with domestic and foreign experts, academic groups, and editorial personnel with extensive experience in journal internationalization to meet the international standards of timeliness, standardization, and diversity of editing and publishing as well as dissemination. We are aiming to establish a first-class journal in the field of military medicine with both Chinese characteristics and international standard.

We sincerely look forward to and warmly welcome the active participation of domestic and international experts with background of military medicine in the production of our journal. Based on our mutual learning, communication, and inspiration, we will establish our mutual trust, enhance our friendship, and strengthen our cooperation. With our combined wisdom and power, the evergreen tree of military medicine will be well-watered. Let's join together and make a positive contribution to safeguarding human health and promoting peace and development of the world!
Authors' information

Director General of the Health Department, General Logistics Department, Chinese People's Liberation Army (PLA).

Chairman of the Committee of Medical Science and Technology (CMST) of PLA.

Received: 31 March 2014 Accepted: 31 March 2014

Published: 15 April 2014

doi:10.1186/2054-9369-1-1

Cite this article as: Ren: Inaugural editorial: Military Medical Research.

Military Medical Research 2014 1:1.

\section{Submit your next manuscript to BioMed Central and take full advantage of:}

- Convenient online submission

- Thorough peer review

- No space constraints or color figure charges

- Immediate publication on acceptance

- Inclusion in PubMed, CAS, Scopus and Google Scholar

- Research which is freely available for redistribution 